\title{
Tibia plato ve proksimal tibia metafiz kaynamamaları
}

\author{
Non-unions of the tibial plateau and proximal tibial metaphysis
}

\author{
Cem Çopuroğlu, Murat Erem \\ Trakya Üniversitesi Tıp Fakültesi, Ortopedi ve Travmatoloji Anabilim Dalı, Edirne
}

\begin{abstract}
Tibia proksimal metafizer bölgesi, diğer kemiklerin metafizer bölgeleri gibi iyi kanlanan, spongiyöz kemikten yoğun bir bölgedir. Kan dolaşımının iyi olması, kaynama açısından avantaj olmakla birlikte, yüksek enerjili yaralanmalar sonucu oluşan tibia plato kırıkları, tibia proksimal metafizer bölge kırıkları ve tibia proksimaline uygulanan tibial osteotomi girişimleri sonrası kaynamama görülebilir. Kaynamamanın az görülmesinin nedeni, yumuşak doku desteğinin iyi ve metafizer bölgenin iyi kanlanıyor olmasıdır. Tedavi seçeneği belirlenirken, kaynamama bölgesindeki biyolojik ve mekanik durum ve hasta ile ilgili sistemik sorunların değerlendirilmesi gerekmektedir. Tibia plato ve proksimal tibia metafizi kaynamamalarında, genel olarak implant değişimi ile tespit dengesinin sağlanması ve otolog kemik grefti ile tedavi esastır.
\end{abstract}

Anahtar sözcükler: tibial plato; kaynamama; tibia metafizi
Proximal tibial metaphyseal region is made of cancellous bone which has a rich vascular supply, like other metaphyseal region of bones. Although it is advantage, non-unions can occur after tibial plateau and proximal tibial metaphyseal fractures resulting from high energy traumas and proximal tibial osteotomies. Tibia plateau and proximal tibia non-unions are rare due to excellent blood supply and soft tissue support. While deciding on treatment options, biological and mechanical conditions of fracture site, and patient's systemic conditions should be evaluated. Main principles of non-union treatment in tibial plateau and proximal tibia fractures are providing fixation balance with implant exchange, and autologous bone graft.

Key words: tibial plateau; non-union; tibial metaphysis
T ibia proksimal metafizer bölgesi, diğer kemiklerin metafizer bölgeleri gibi iyi kanlanan, spongiyöz kemikten yoğun bir bölgedir. Kan dolaşımının iyi olması, kaynama açısından avantaj olmakla birlikte, yüksek enerjili yaralanmalar sonucu oluşan tibia plato kırıkları, tibia proksimal metafizer bölge kırıkları ve tibia proksimaline uygulanan yüksek tibial osteotomi girişimleri sonrası kaynamama görülebilir (Şekil 1).

Tibia plato kırıkları tüm kırıkların \%1-2'sini oluşturur ve yaşamın 50 yılı boyunca görülme sıklığı açısından yetişkin kırıklarının üçüncü sırasında yer alır. ${ }^{[1,2]}$ Tibia üst uç eklemini içeren tibia plato kırıkları, hafif şiddetteki yaralanmalarla oluşan basit kırıklardan, yüksek şiddetteki yaralanmalarla oluşan kompleks kırklara kadar geniş dağılım gösterir. ${ }^{[3,4]}$

Trafik kazası, tampon darbesi, yüksekten düşme veya spor yaralanmaları gibi etkenler, etiyolojik nedenler olabilir. Yüksek enerji ile meydana gelen kırıklar daha çok genç yaşlarda görülürken, düşük enerji ile meydana gelen kırıklar genellikle ileri yaşlarda görülmektedir. Travmanın şiddeti ve kemiğin kalitesi kırığın parçalanma oranını ve deplasman miktarını belirler. ${ }^{[5]}$ Tibia platosuna ait avulsiyon kırıkları ise diz çıkıkları ve diğer diz bağ yaralanmaları ile birlikte meydana gelebilmektedir. ${ }^{[1]}$

Tedavi seçenekleri, eklemin açık redüksiyonu, plakvida ile tespiti, artroskopi veya skopi yardımlı perkütan vida tespiti, eksternal tespit, alçı veya traksiyon uygulamasına kadar geniş bir yelpazededir. ${ }^{[5]}$ Ancak, müdahalenin zamanı ve şekline karar vermede hayati önem taşıyan en önemli faktör, hastanın komorbiditeleriyle birlikte çevre yumuşak doku hasarıdır. ${ }^{[2]}$

Redüksiyon kaybı, yara sorunu ve yumuşak doku enfeksiyonu, septik artrit, diz sertliği, ağrı, non-union, malunion ve travma sonrası artroz gibi komplikasyonlar gözlenebilmektedir. ${ }^{6-10]}$

- Illetişim adresi: Prof. Dr. Cem Çopuroğlu, Trakya Üniversitesi Tıp Fakültesi, Ortopedi ve Travmatoloji Anabilim Dalı, Edirne Tel: 0532 - 3361923 e-posta: cemcopur@hotmail.com

- Geliș tarihi: 1 Kasım 2017 Kabul tarihi: 1 Kasım 2017 


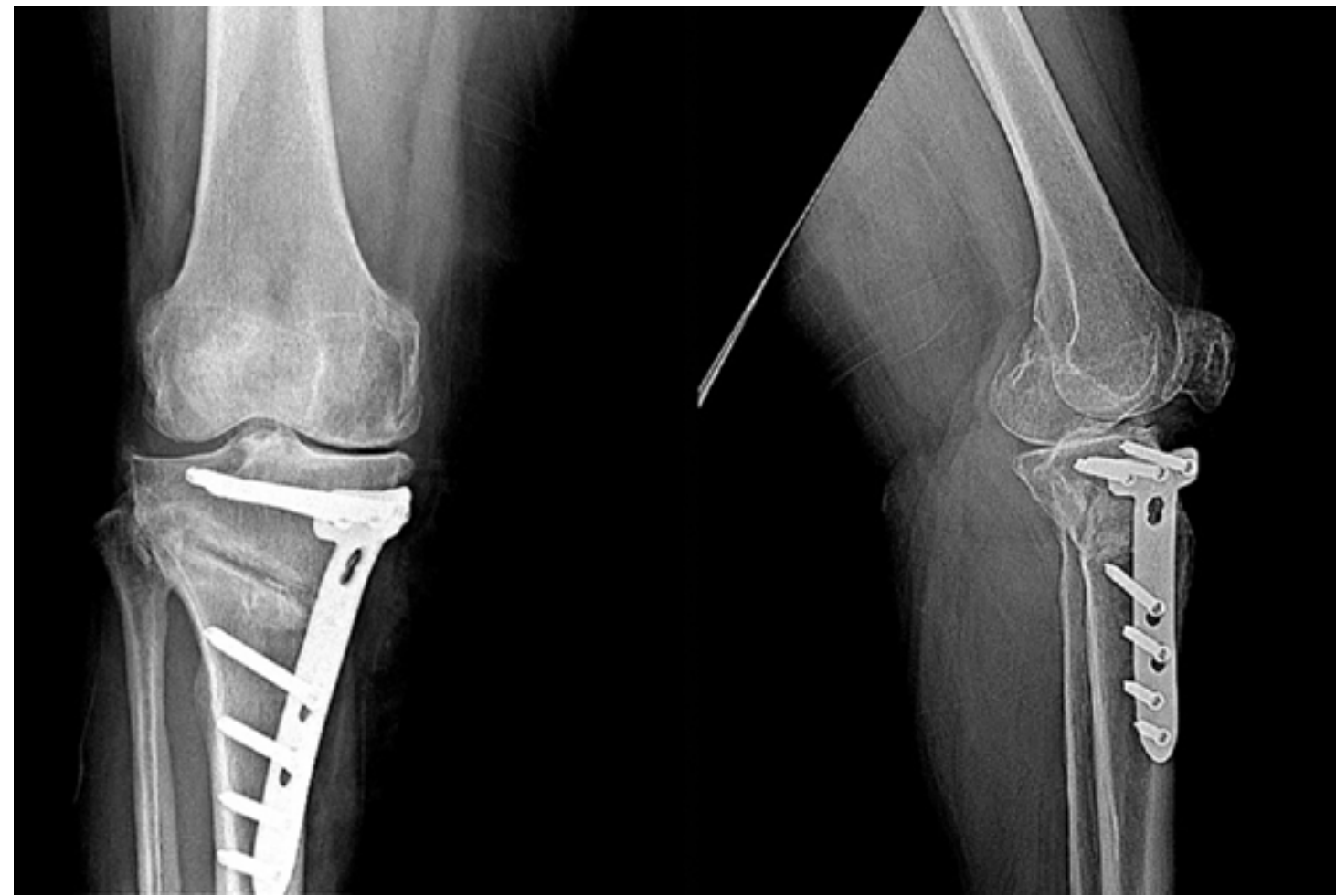

Şekil 1. Yüksek tibial osteotomi girişimleri sonrası kaynamama.

\section{TANI ve DEĞERLENDIRME}

Birçok araştırmada kaynamama, konservatif ya da cerrahi tedavi sonrası en az dokuz ay geçmiş ve beklenen kaynama süresinin üzerinden 2-3 ay geçmesine rağmen kırıkta klinik ve radyolojik ilerleme olmaması olarak kabul edilmiştir. ${ }^{[11,12]}$

Tibia plato ve proksimal metafiz kırıklarında kaynamama, tibianın diğer bölgelerini ilgilendiren kırıklarına göre nadir görülen bir komplikasyondur. ${ }^{[1,5]}$ Kaynamamanın az görülmesinin nedeni, yumuşak doku desteğinin iyi ve metafizer bölgenin iyi kanlanıyor olmasıdır. Kaynamama en sık Schatzker Tip 6 (bikondiller) kırıklarda gözlemlenir ve kaynamaması halinde tedavisi zordur. ${ }^{[1,13]}$ Bu nedenle, cerrahi tedavi endikasyonu olan tibia plato kırıklarında cerrahi tedavi yöntemi belirlenirken, yumuşak dokuların durumuna en uygun olan cerrahi teknik seçilmeli, zamanlama doğru yapılmalı, gereksiz ve aşırı insizyonlardan kaçınılmalıdır. ${ }^{[2,5]}$ Ayrıca, kırık iyileşmesine olumsuz etkileri olan diyabet, protein malnütrisyonu, analjezik kullanımı, sigara kullanımı ve osteoporoz gibi sistemik etmenler kontrol altına alınmalıdır. ${ }^{[14]}$

Kırık hattında patolojik hareketin varlığı ve ağrı olması, kaynamama düşündüren klinik bulgulardır.
Ayrıca, şişme, ısı artışı, kızarıklık gibi lokal enfeksiyon bulguları da septik kaynamamaya işaret eder. Tedavi planının belirlenmesinde ilk ekarte edilmesi gereken enfeksiyon varlığıdır. ${ }^{[1,11]}$ Laboratuvar testi olarak CRP (C-reactive protein), sedimentasyon ve lökosit sayımı ekartasyon için istenebilecek ilk tetkiklerdir. ${ }^{[11]}$

Tibia plato kırıklarını değerlendirmek için, ön-arka, yan, oblik grafilere ve bilgisayarlı tomografi (BT) görüntülerine gereksinim vardır. Eklem yüzeyindeki ayrışma ve çökme miktarını tespit etmek gerekir ve bunu tespit etmede BT oldukça yol göstericidir. Ayrıca 3D tomografi görüntülemeleri de yaygın olarak kullanılmaktadır. ${ }^{[15]}$ Sınıflamada, Schatzker ve AO/ASIF sınıflamaları yaygın olarak kullanılır. ${ }^{[5]}$

Kaynama, dört korteksten en az üçünde kortikal devamlılığın görülmesi olarak kabul edilir. ${ }^{[16]}$ Eklem içi kırıklarda anatomik redüksiyon ve rijid tespit (primer kemik iyileşmesi) hedeflenmesi nedeniyle kallus görülmek istenmez. ${ }^{[5,17]}$ Açılanma ve deformite gözlenebilir. Anatomik olmayan redüksiyon ile tedavi edilmiş tibia plato kırıklarında, eklem içi sinoviyal sıvının kırık hattına girmesi, kaynamayı olumsuz etkiler. Ayrıca, radyolojik olarak kullanılan implantlarda yetmezlik görülebilir. Başlangıçta hedeflenen kemik 
iyileşmesi tipine göre kallus oluşması veya oluşmaması, kaynamamaya işaret edebilir. ${ }^{[5,17]}$ Psödoartroz oluşumu ise yıllar süren bir sürecin sonucudur. Klinik olarak ağrısızdır ve sadece cerrahi yöntemlerle tedavi edilebilir. ${ }^{18]}$ Kırığın açık kırık olması, hastanın sigara, alkol kullanımı, kronik sistemik hastalıkları, kırık hattının uygun olmayan redüksiyonu, kırık uçları arasına yumuşak doku veya sinoviyal sıvı girmesi gibi etkenler, kaynamama nedeni olarak karşımıza çıkabilir. ${ }^{[19]}$

\section{TEDAVi}

Tedavi seçeneği belirlenirken kaynamama bölgesindeki biyolojik ve mekanik durum ve hasta ile ilgili sistemik sorunların değerlendirilmesi gerekmektedir. Tibia plato ve proksimal tibia metafizi kaynamamalarında genel olarak implant değişimi ile tespit dengesinin sağlanması ve otolog kemik grefti ile tedavi esastır. ${ }^{[10,20]}$

Proksimal tibia metafizi kırıklarında kaynama problemi en sık Schatzker Tip V ve Tip VI kırıklarda görülür. $\mathrm{Bu}$ bölgenin kırıklarında tespit sırasında erken greftlenme önerilmektedir. ${ }^{[5,21]}$

Ameliyatsız tedavi seçeneği olarak; lokal enjekte edilebilen kemik iliği, trombosit açısından zengin plazma (PRP) veya kemik morfojenetik proteinin (BMP) biyolojik ve biyokimyasal aktiviteyi arttırıcı etkilerinden dolayı kullanılabilir. Ayrıca, biyolojik stimülasyon fiziksel ajanlarla da yapılabilir. Ultrasonografi veya elektromanyetik alan kullanılabilir. ${ }^{[22]}$ Sjoerd Rutten ve ark.'nın 71 hasta üzerinde yapmış oldukları çalışmada, düşük yoğunluklu darbeli ultrasonografi kaynamama tedavisinde etkili ve tibia kaynamamaları tedavisinde iyi, güvenli ve cerrahi tedaviden daha ucuz bir alternatif tedavi yöntemi olarak değerlendirilmiştir. ${ }^{[23]}$

Kansellöz otogreftler, dekortikasyon işlemi ile birlikte kırık hattında biyolojiyi aktifleştirmenin temel materyalleridir. Osteoindüktif, osteokondüktif ve osteojenik olmaları, bunları allogreftlerden üstün kılar. Dezavantajları ise, sınırı miktarda alınabilmeleri ve donör sahada ağrıdır. ${ }^{[24,25]}$ Giannoudis ve ark. tarafından tanımlanan diamond konsept, osteojenik hücrelerden, osteokondüktif kafes implantlarından, büyüme faktörlerinden ve mekanik implantlardan oluşmaktadır ve kaynamama tedavilerinde önerilmektedir. ${ }^{26,27]}$

Tespit yetersizliğine bağlı gelişen kaynama yokluğunda, implant revizyonu ya da değişimi düşünülmelidir. Internal tespite tamamlayıcı eksternal tespit uygulanabileceği gibi, mevcut eksternal tespit internal tespite de dönüştürülebilir. Ayrıca, mevcut internal tespit materyalinin redüksiyonunu düzeltmek ya da farklı bir internal tespit materyali ile revizyon yapmak da mümkündür. ${ }^{[22]}$ Tedavi stratejisi belirlenirken en önemli belirteç, yumuşak doku desteğinin durumudur. ${ }^{[28]}$
Tibia platosunun eklem içi kırıklarında kaynamama görüldüğünde tedavi seçeneği, artroz bulguları ve eklem hareket açıklığı göz önünde bulundurularak belirlenmelidir. Eklemin kaynamamasının yanı sıra oluşan deformite, alt ekstremitenin doğru hizalanmamasına neden olacaktır. Eklemin kurtarılabileceği durumlarda, eklem rekonstrüksiyonu sonrası internal ya da eksternal tespit yapılarak greftler ve osteoindüktif malzemeler kullanılmalıdır. Eklemin kurtarılamayacağı durumlarda ise diz artrodezi ya da artroplastisi tercih edilebilir. ${ }^{[1]}$

Sonuç olarak; kaynamama nadir görülmesine rağmen, tibia plato ve proksimal tibia metafiz kırıkları tedavisi büyük bir titizlikle planlanmalı, yumuşak doku iyi değerlendirilmeli ve uygun tespit yöntemi seçilmelidir. Gerektiğinde tespit esnasında greftleme yapılması, kaynamama riskini azaltacaktır. Tespit materyalleri kombine edilerek, uygun redüksiyon ve tespit sağlanmalıdır. Ayrıca, erken eklem hareketi ve erken yük verme de kaynama üzerine olumlu etki yapmaktadır.

\section{KAYNAKLAR}

1. Bucholz RW, Heckman JD, Court-Brown CM, Tornetta P, editors. Rockwood and Green's Fractures in Adults, 7th ed. Philadelphia, PA: Wolters Kluwer Health, Lippincott Williams \& Wilkins; 2010. p.1780.

2. Kokkalis ZT, Iliopoulos ID, Pantazis C, Panagiotopoulos E. What's new in the management of complex tibial plateau fractures? Injury 2016;47(6):1162-9. Crossref

3. Hohl M. Part 1: Fractures of the proximal tibia and fibula. In: Green D, Bucholz R, editors. Fractures in Adults, 3rd ed. Philadelphia, PA: JB Lippincott; 1991. pp.1725-61.

4. Başoğlu O. Tibia Plato Kırıkları. Zonguldak Karaelmas Üniversitesi Tıp Fakültesi Dergisi Medi ForuM 2014;1(2):28-39.

5. Küçükkaya M. Tibia plato kırıkları. TOTBiD Derg 2008;7(1-2):67-71.

6. Hall JA, Beuerlein MJ, McKee MD; Canadian Orthopaedic Trauma Society. Open reduction and internal fixation compared with circular fixator application for bicondylar tibial plateau fractures. Surgical technique. J Bone Joint Surg Am 2009;91 Suppl 2 Pt 1:74-88. Crossref

7. Ebraheim NA, Sabry FF, Haman SP. Open reduction and internal fixation of 117 tibial plateau fractures. Orthopedics 2004;27(12):1281-7.

8. Gösling $\mathrm{T}$, Schandelmaier $\mathrm{P}$, Marti A, Hufner $\mathrm{T}$, Partenheimer A, Krettek C. Less invasive stabilization of complex tibial plateau fractures: a biomechanical evaluation of a unilateral locked screw plate and double plating. J Orthop Trauma 2004;18(8):546-51.

9. Hsu CJ, Chang WN, Wong CY. Surgical treatment of tibial plateau fracture in elderly patients. Arch Orthop Trauma Surg 2001;121(1-2):67-70.

10. Jiang R, Luo CF, Wang MC, Yang TY, Zeng BF. A comparative study of Less Invasive Stabilization System (LISS) fixation and two-incision double plating for the treatment of bicondylar tibial plateau fractures. Knee 2008;15(2):139-43. Crossref

11. Reisoğlu $A$, Ağuş $H$. Kaynamamalarda (psödoartoz) tanı ve tedavi. TOTBID Derg 2008;7(1-2):72-80. 
12. Chapman MW, Szabo RM, Marder RA, editors. Chapman's Orthopaedic Surgery, 3rd ed. Vol 10. Philadelphia, PA. Lippincott Williams \& Wilkins; 2001.

13. Mahadeva D, Costa M, Gaffey A. Open reduction and internal fixation versus hybrid fixation for bicondylar/severe tibial plateau fractures: a systematic review of the literature. Arch Orthop Trauma Surg 2008;128(10):1169-75. Crossref

14. Calori GM, Albisetti W, Agus A, lori S, Tagliabue L., Risk factors contributing to fracture non-unions. Injury 2007;38 Suppl 2:S11-8.

15. Castiglia MT, Nogueira-Barbosa MH, Messias AMV, Salim R, Fogagnolo F, Schatzker J, Kfuri M. The impact of computed tomography on decision making in tibial plateau fractures. J Knee Surg 2018. Crossref

16. Den Boer FC, Patka P, Bakker FC, Haarman HJThM. Current concepts of fracture healing, delayed unions, and nonunions. Osteo Trauma Care 2002;10(1):1-7. Crossref

17. Ruedi TP, Buckley RE, Moran CG. AO principles of fracture management, 2nd exp. ed. Books and DVD. New York: Thieme; 2007.

18. Frölke JPM, Patka P. Definition and classification of fracture non-unions. Injury 2007;38 Suppl 2:S19-22.

19. Copuroglu C, Calori GM, Giannoudi PV. Fracture non-union: who is at risk? Injury 2013;44(11):1379-82. Crossref

20. Olson S, Hahn D. Surgical treatment of non-unions: A case for internal fixation. Injury 2006;37(8):681-90. Crossref
21. Watson JT. High-energy fractures of the tibial plateau. Orthop Clin North Am 1994;25(4):723-52.

22. Tall M. Treatment of aseptic tibial shaft non-union without bone defect. Orthop Trauma Surg Res 2018;104(Suppl 1):S63-9. Crossref

23. Rutten S, Nolte PA, Guit GL, Bouman DE, Albers GH. Use of low-intensity pulsed ultrasound for posttraumatic nonunions of the tibia: a review of patients treated in the Netherlands. J Trauma 2007;62(4):902-8. Crossref

24. Phieffer LS, Goulet JA. Delayed unions of the tibia. J Bone Joint Surg Am 2006;88(1):206-16.

25. Sen MK, Miclau T. Autologous iliac crest bone graft: should it still be the gold standard for treating nonunions? Injury 2007;38 Suppl 1:S75-80. Crossref

26. Giannoudis PV, Einhorn TA, Marsh D. Fracture healing: the diamond concept. Injury 2007;38 Suppl 4:S3-6.

27. Moghaddam A, Zietzschmann S, Bruckner T, Schmidmaier G. Treatment of atrophic tibia non-unions according to 'diamond concept': Results of one- and two-step treatment. Injury 2015;46 Suppl 4:S39-50. Crossref

28. Biggi F, Di Fabio S, D’Antimo C, Trevisani S. Tibial plateau fractures: internal fixation with locking plates and the MIPO technique. Injury 2010;41(11):1178-82 Crossref 